in a series of conclusions, sums up the reasons why the objects seen were nothing like telescopic meteors, and these are as follows:-They require a longer focus than the sun; they did not move in parallel directions; their general direction agreed with the direction of the prevailing wind; they were objects of irregular shape and light filamentous material; their vagaries of motion while in sight were greatly dissimilar to that of true telescopic meteors seen at night; and, finally, on one occasion Mr. Denning followed them on several successive days and a change occurred in the directions. These showers, they state, are purely local terrestrial events. In most cases they are seeds or the down of various plants carried by the wind at high elevations. In some cases snowflakes are the cause of the phenomenon, whilst insect-swarms, gossamer-threads, etc., are sometimes observed. Prof. Barnard states that at certain seasons of the year they can be seen in abundance when the telescope is pointed within a few degrees of the sun, giving the greatest angle of reflection, and if moving slowly appear like minute stars.

Stars having Peculiar Spectra.-In Circular No. 184 of the Harvard College Observatory Prof. E. C. Pickering publishes an additional list of stars having spectra with bright lines or other peculiarities found by Miss Cannon since the publication of Circular 178 , which contained a list of peculiar objects in the course of the work on the new Draper Catalogue. The first table in the new circular gives a list of fourteen stars, six of which are described as new variables. In Table II. a list of thirty-one stars having composite spectra, including twenty-four new double stars, is given, and this brings the number of stars with composite spectra found on the Harvard photographs up to Ioo. The stars in this table range from magnitude 5.32 to $10 \cdot 6$, and the class of spectrum of the brighter and fainter components, as they have been determined from the general appearance of the blended spectra, are given in each case. In both tables the stars are arranged in order of Right Ascension, with the corresponding Durchmusterung numbers.

\section{EFFECTS OF THE WAR ON SCIENTIFIC UNDERT'AKINGS.}

GEVERAL international or otherwise co-operative investigations of a scientific kind which were in progress at the opening of the war have necessarily been affected by the naval and military operations and the limitation of usual channels of communication. It is not opportune to state the position of some of these undertakings at the present moment, but various negotiations are proceeding, and it is hoped that a means will be found of carrying on work already well begun. The incalculable loss which scientific research must bear in the suspension of the international fishery investigations was referred to in an article in NATURB of October 22 (p. 20I). Reference has also been made (NATURE, October 15, p. 183) to the need for a central bureau for the distribution of astronomical telegrams, as was done before the war by the Zentralstelle at Kiel. A few weeks after that note appeared Prof. Elis Strömgren, director of the University Observatory at Copenhagen, announced that by an agreement made between Prof. Kobold, of Kiel, as publisher of the Astronomische Nachrichten, and himself, the management of the Zentralstelle für astronomische Telegramme during the present war has been passed over to Prof. Strömgren. Consequently, all communications for the Zentralstelle should be addressed to him until further notice at the Observatory, Copenhagen.

The work of the Tropical Diseases Bureau in NO. 2354, VOL. 94]
London has diminished since the outbreak of the war owing to the non-receipt of French and German journals; for the bureau exists primarily for the collection of information, chiefly from medical journals, on the diseases of tropical and subtropical climates, and its collation and dissemination within the pages of a journal, the Tropical Diseases Bulletin. There is little doubt that such investigations are being hampered in Africa by operations of war, and that they will be seriously interfered with in the future owing to lack of funds now derived both from the home Government and the tropical dependencies of Great Britain.

As to the future of the International Catalogue of Scientific Literature, the report of the council of the Royal Society states that the responsibilities of the society in relation to this undertaking have been a source of anxious consideration since the outbreali of the war. Apart from the question of continuance, the society is faced with serious liabilities in respect of this undertaking as it stands at the present moment. Should the annual amount of the subscriptions from Germany, Austria, Hungary, Belgium, and Poland not be available, as seems certain, at any rate until after the close of the war, this would mean an annual loss of about ro6ol. in income in respect of each issue, or a total loss of about $4000 \mathrm{l}$. on the issues of rgII, I9I2, and $19 I_{3}$, after taking into account reduction of expenditure and in sales of trade copies and back numbers. This loss will fall, at any rate in the first instance, on the Royal Society.

Daily Weather Maps.-me Quarterly Journal of the Royal Meteorological Society (October, IgI4) prints the subjoined note on the effect of the war on the issue of daily weather maps :-The sudden outbreak of war has a very marked effect upon the compilation and publication of the various daily weather maps. The Daily Weather Report issued by the Meteorological Office contained the usual information until July $3 \mathrm{I}$, but after that date some of the observations began to be missing, while from August 6 no data have been received from central Europe, and the wireless reports from the Atlantic were altogether discontinued. For several weeks the reports from Scandinavia and Spitsbergen were missing, but these were resumed in September, though reports from Iceland are still absent. The difficulties of preparing the usual forecasts and storm-warnings have consequently been much increased. The publication of the daily synoptic weather maps of Europe, the North Atlantic, and a large portion of North America, which has formed part of the Weekly Weather Report, has been suspended from August 2, until the necessary data have been received.

It has been the practice of the Times newspaper since $18-6$ to print each day the previous 6 p.m. weather map. This was continued until August 4, but after that date no further map appeared-no doubt owing to all the available space in the newspaper being urgently required for war information. For the same reason the table of observations from health resorts was discontinued from August 3 .

On August 6 the Chief of the U.S. Weather Bureau announced that "owing to the state of war involving the great nations of Europe, the meteorological observations from regions in Europe and Asia, heretofore employed by the Weather Bureau in the construction of its weather map of the northern hemisphere, are no longer received, and the issue of this map will be suspended from this date until such time as the reports can be resumed."

Investigations of the Upper Air.-The effect of the war upon investigations of the upper air so far has only been indirect in the British Isles, but several independent causes have led to the fact that the present year has not been as fruitful of resulfs as 
previous years, and the difficulty of getting rubber balloons of really good quality has been greatly intensified by the war. During both IgI2 and I9I3 between fifty and sixty satisfactory balloon ascents were obtained, but the average maximum height in I9I3 showed a distinct falling off compared with previous years. This was due to the balloons, of which the quality and workmanship are of the utmost importance. During the present year, although fresh sources of supply have been tried, the quality of the balloons has still further deteriorated, with the result that in many cases a premature bursting of the balloon has occurred and a maximum height of some five only instead of some fifteen kilometres has been attained. Since the details of the ascents have remained the same, the poor heights reached must be due to defective balloons.

There is an old proverb that misfortunes never come singly. The ascents at Manchester have ceased since the beginning of this year, and a run of persistent ill-luck in the finding and return of the instruments has been experienced; also the station of the Meteorological Office at Pyrton Hill, Watlington, ceased to be available in the spring. The present station is at Benson, about six miles W.S.W. of Pyrton Hill, a place equally suitable, but the compulsory removal of the station dislocated the regular routine work of the investigation during the first half of the year. From these various causes the number of successful balloon ascents this year in the British Isles can scarcely reach twenty-five, since the war has, for the time being, cut off the supply of balloons, and the very poor returns from the first half of the year cannot be made up by an extra number of ascents in the latter part.

It has been an unsatisfactory state of affairs that balloons should have been obtained from foreign firms, but chesper and better balloons were so obtainable. It is hoped that arrangements may shortly be made for the supply from an English firm.

There is another way in which the investigation may be influenced by the war. In England compressed hydrogen can be obtained cheaply and conveniently in steel cylinders, but in some of our colonies these cylinders cannot be obtained. Failing this source of supply hydrogen is most easily produced from calcium hydride, the free lift of the hydrogen in air being equal to the weight of hydride used. Apparently the calcium hydride can only be obtained in Germany.

There is no information about what is occurring on the Continent. The international days are fixed until the end of the year, but after December, if ascents continue in Germany and Austria, it does not seem likely that we shall know the dates. Also the meeting of the International Committee which was to have been held in England next year can scarcely now take place.

In the investigation of the upper air the value of the individual observations is decidedly increased by a well-planned system of co-operation, but happily there are many problems which may be attacked without such co-operation, and we may hope that the work may go on with equal vigour as in the past, excepting that the necessary funds are not likely to be increased by the heavy expenses due to the war.

International Seismological Association. - The fifth meeting of the International Seismological Association was to have been held early last September at Petrograd, under the presidency of Prince Galitzin. Soon after war was declared, it was announced that the meeting was postponed, and, indeed, with the president a Russian, the secretary a Hungarian, and a committee including Germans, Englishmen and Japanese, no other result could be expected. The formal meeting of the association once every two or

NO. 2354 , VOL. 94] three years is not, however, the most useful work carried out under its auspices. The permanent coma mittee of the association, with its headquarters at Strassburg, was engaged in collecting materials that could not fail to be of the greatest service. The compilation of the annual catalogues of perceptible earthquakes and of those registered at distant stations would alone justify the existence of the Association. To all this useful work, there must for the present be an end, and, even if the threads of the organisation are ultimately resumed, there will be a long delay in the issue of the next catalogues, and there will be many imperfections in the lists of perceptible shocks. In the registers of seismological observatories, the effect of the war will probably be less serious, for the network of stations established in the British Colonies and in allied and neutral countries is practically world-wide. The late Prof. Milne's decision to maintain the organisation which he created outside the control of the International Association is thus likely to have most beneficial results.

\section{THE NATURAL HISTORY MUSEUM IN THEORY AND PRACTICE. ${ }^{1}$}

$D^{R}$. GUSTAVE GILSON, director of the Royal Belgian Museum of Natural History, has recently given to the scientific world his views on the general theory of a natural history museum in a magnificent quarto volume. The following is a brief abstract of his conclusions.

A universal museum being obviously impracticable, a regional museum is all that can be attempted, and the "region" must be limited according to circumstances. The collections of the museum must bc acquired by systematic observations conducted by one or more officials (chefs d'exploration) specially trained for this particular work, and the exploration must include the acquisition not merely of individual specimens, but also of such material, drawings, plans, photographs, and records as are needed to give a full account of the environment. "The museum ought only to accept with suspicion a specimen that has not been collected by its own officials and furnished with data written down at the moment of its discovery."

The museum is not primarily an institution for the dissemination of scientific information among the populace, but a progressve institution dedicated to the advancement of knowledge, free from all pedagogic trammels and from every preoccupation alien to the investigation of nature, and thus playing an important part in the humanitarian mission of the development of natural history: "le musée renseigne, mais n'enseigne pas." Nevertheless, the museum may without being false to its ideals, expound to the people many of the results of its work, and become a valuable teacher in a line, and by methods different from those of the schoolmaster.

The regional museum must preserve collections on a generous scale, but these must be properly kept in suitable storehouses (conservatoires) under the constant supervision of trained curators (conservateurs). Dr. Gilson makes some strong remarks on the failure of many museums to take due care of their treasures. Besides the main collections there should be others, such as the "comparative" department, containing examples of similar objects from other places for study in connection with those of the region. These specimens may, of course, be acquired by gift or purchase. There should also be a public collection of examples judiciously selected; " here everything useless is harm-

1 "Le Musée d'Histnire Naturelle Moderne-sa mission, son organisation, ses droits." Extrait des Memoires du Musée royal d'Histoire naturolle de Belgique. By G. Gilson. Pp. xii +256 . (Bruxelles: l'Académie Royale de Belgique, 1914.) 